\title{
Sport participation after the HandbikeBattle: benefits, barriers, facilitators from the event-a follow-up survey
}

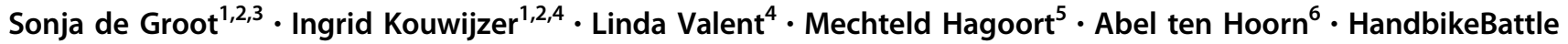 \\ group $\cdot$ Lucas van der Woude ${ }^{2,7} \cdot$ Marcel Post $\mathbb{D}^{7,8}$
}

Received: 13 May 2020 / Revised: 13 June 2020 / Accepted: 15 June 2020

(c) The Author(s), under exclusive licence to International Spinal Cord Society 2020

\begin{abstract}
Objectives To investigate sports participation among individuals in the HandbikeBattle project 1.5-5.5 years after the event, the barriers and facilitators to sport participation and benefits of participating in the event.

Setting Former participants of the HandbikeBattle, a handcycling race on an Austrian mountain.

Methods Handcyclists who took part in one or more HandbikeBattle events in 2013-2017 were invited to complete a survey in December 2018. Questions were asked on benefits of participating in this event, current sport participation, and experienced barriers and facilitators regarding current sport participation.

Results Respondents $(N=96(N=59$ with spinal cord injury (SCI) or Spina Bifida (SB)), response rate $=47 \%)$ reported benefits from this event regarding their fitness level (90\%), personal development (81\%), daily life activities (66\%), and health (64\%). Median current sport participation was $5 \mathrm{~h} /$ week (IQR: 3-8). Most frequently indicated personal barriers for sports participation were: lack of time (31\%), disability (17\%), and pain (15\%). Most frequently mentioned environmental barriers were: transportation time to sport accommodation (19\%), and lack of peers to do sports with (16\%). Most important facilitators were motivation to improve health and/or fitness (92\%), fun and/or relaxation (85\%). The results for the subgroup with SCI were comparable with the results of the total group.

Conclusions Results highlight the role sports challenges can have in establishing a sustainable active life lifestyle among people with disabilities.
\end{abstract}

Members of the HandbikeBattle group are listed below

Acknowledgements.

Sonja de Groot

s.d.groot@ reade.nl

1 Amsterdam Rehabilitation Research Center, Reade, Amsterdam, The Netherlands

2 University of Groningen, University Medical Center Groningen, Center for Human Movement Sciences, Groningen, The Netherlands

3 Department of Human Movement Sciences, Faculty of Behavioural and Movement Sciences, Vrije Universiteit Amsterdam, Amsterdam, The Netherlands

4 Research and Development, Heliomare Rehabilitation Center, Wijk aan Zee, The Netherlands

\section{Introduction}

People living with a disability are often less physically active compared with their able-bodied peers [1]. Multiple personal and environmental barriers to physical activity have been described in the literature [2,3]. This is a concern

5 Sport Department, Heliomare Rehabilitation Center, Wijk aan Zee, The Netherlands

6 Sport Department, Rehabilitation Centre De Hoogstraat, Utrecht, The Netherlands

7 University of Groningen, University Medical Center Groningen, Center for Rehabilitation, Groningen, The Netherlands

8 Center of Excellence for Rehabilitation Medicine, UMCU Brain Center, University Medical Center Utrecht and De Hoogstraat Rehabilitation, Utrecht, The Netherlands 
since being physically active and fit are related to health [4] and quality of life [5].

Interventions to enhance physical activity levels among wheelchair-users are therefore, highly important [6]. The HandbikeBattle [7] is an annual event in which teams consisting of former patients from 12 Dutch rehabilitation centers handcycle up a mountain. With 20-km length and nearly $900-\mathrm{m}$ elevation gain, it is a challenge that requires considerable training to complete. Handcyclists are advised by rehabilitation professionals, e.g., physical therapists, occupational therapists, and physical educators, but they train on their own or with other team members for $\sim 5$ months prior to the event. Recent studies showed that training for the HandbikeBattle leads to positive short-term effects on physical fitness and physical and mental health [8-10]; however, the ultimate goal of the HandbikeBattle is that participants experience positive effects on performance of activities in daily life and in their personal development, and participate in sports on an ongoing basis. Therefore, the aims of this follow-up survey 1.5-5.5 years after the event were to study: (1) experienced benefits of participation in the HandbikeBattle, (2) ongoing sports participation, and (3) experienced barriers and facilitators of current sport participation, and whether these differ between those who were more/less involved in sports $1.5-5.5$ years after the event or participated once or multiple times in the event.

\section{Method}

\section{Participants}

Inclusion criteria for the HandbikeBattle project were being a former rehabilitation patient from one of the participating rehabilitation centers; impairment of the lower extremities due to e.g., spinal cord injury (SCI), spina bifida (SB), amputation, or cerebral palsy; and commitment to complete the $\sim 5$ months training and the HandbikeBattle event. Exclusion criterion was: contraindications to participate in the HandbikeBattle as diagnosed during the medical screening.

Each year, potential HandbikeBattle competitors are invited to participate in an observational study designed to monitor their health, fitness, and quality of life. All 203 participants in this study in 2013-2017 were invited for the current follow-up study in December 2018.

\section{Procedures}

Potential respondents received an invitation email with information on the study and a link to an online survey. Completing the survey took about 5-10 min and potential respondents received two reminders via email. Participants signed an informed consent before the start of the study. The ethical committee of the Center of Human Movement Sciences of the University Medical Center Groningen approved the HandbikeBattle study (ECB/2012_12.04_1_rev) and the current follow-up study (ECB/2016.02.02_1R1).

\section{Survey}

\section{Experienced benefits/losses}

The following question was asked-'Looking back at the total HandbikeBattle project (i.e., training preparation, the mountain time trial, the HandbikeBattle week in Austria among peers), in which domains have you experienced losses or benefits of participation when taking your current situation into account?' The five domains were: fitness (e.g., condition, strength), health (e.g., being ill, pressure sores, etc.), handcycling (e.g., skill, tactics, knowledge material), performance of activities in daily life (ADL) (e.g., independence), and personal development (e.g., self-confidence, motivation). The 9-point Likert score per domain varied from very much loss via no benefits/losses (neutral) to very many benefits.

\section{Exercise and sports participation}

The first question was 'What exercise/sport do you practice currently?'. Per mentioned exercise/sport the participant was asked for the average hours per week during the last 3 months. The same questions had been asked for the pretraining situation at the time of the medical screening for the HandbikeBattle.

\section{Experienced barriers and facilitators}

An existing questionnaire on barriers to and facilitators of sports participation was used with minor adjustments to make it more relevant for participants of the HandbikeBattle [11]. Four categories of personal and environmental factors were provided and respondents had to check whether or not a factor applied to them. Per category a sum score reflecting the number of checked factors was calculated: personal barriers (range 0-12); environmental barriers (0-17); personal facilitators (0-12), and environmental facilitators (0-3).

\section{Statistics}

Differences between responders and nonresponders to the follow-up survey at the start of training for the HandbikeBattle were checked with an independent $t$-test or Chisquare test.

Descriptives were calculated. Nonparametric tests were used because most variables were not normally distributed. 
Current sport participation (hours/week) was compared with sport participation just before the start of training for the HandbikeBattle with a Wilcoxon Signed Rank Test.

Sport participation was dichotomized in two categories ( $\leq 5$ sport hours/week and $>5$ sport hours/week) based on the median score. Differences in experienced benefits and in the sum scores of experienced barriers and facilitators of sport participation between groups that were more or less actively involved in sport at the time of the follow-up study were tested with a Chi-Square test and Mann-Whitney $U$ test, respectively. Further, differences between these two groups in each barrier/facilitator separately were explored. Because of the many barriers/facilitators, these differences were not tested for significance to avoid chance findings or a very strict correction for multiple testing.

In the same way, differences were tested in experienced benefits, sport participation and experienced barriers/facilitators between groups that participated only once or multiple times in the HandbikeBattle event and between groups that participated in their (last) HandbikeBattle more (0.5-1.5 years before the study) or less (2.5-5.5 years before the study) recently.

Significance was set at $p<0.05$ for all statistical analyses.

\section{Results}

The survey was sent to 203 participants of the 2013-2017 HandbikeBattle events and 96 (47\%) individuals completed the survey, among which 59 had a SCI or SB. Since the results of this subgroup with SCI/SB were similar to the total group, the statistical tests were not repeated for this subgroup. The only significant difference between responders and nonresponders was found in age, with the responders being older (Table 1). Of the responders, 44 participated in the HandbikeBattle event once, while 52 participated multiple times.

\section{Experienced benefits}

The majority of respondents reported they experienced benefits of participating in the HandbikeBattle on each domain (Fig. 1). Most responders reported they experienced benefits in fitness (90\%), handcycling (87\%), and personal development $(81 \%)$. A few participants experienced loss in health $(8 \%)$, fitness $(5 \%)$, personal development $(1 \%)$, handcycling $(1 \%)$, and ADL (1\%). The distribution of answers was similar for the group with SCI or SB (Fig. 1).

No differences were found between groups that were more or less actively involved in sport at the time of the follow-up study or between groups participating in their (last) HandbikeBattle more or less recently. In contrast,
$20 \%$ of the respondents who participated once in the HandbikeBattle experienced losses in contrast to only $2 \%$ of those who participated multiple times $(p=0.005)$.

\section{Sport participation}

The median current sport hours/week was 5.0 (interquartile range (IQR): $3.0-8.4 ; N=96$ ), with nine respondents indicating that they were not involved in sports. Exercises and sports that were mentioned the most were: handcycling $(N=80)$, fitness/strength training $(N=40)$, and swimming $(N=10)$. Degree of sports participation was compared between pre HandbikeBattle training and at the current (follow-up) time for 66 respondents, showing no significant differences between current (Median: 5.3 (IQR: 3.0-7.4)) and previous sport participation (Median: 5.3 (IQR: $3.0-7.5) ; p=0.92$ ). There were no significant differences in sport hours/week between the groups that participated more versus less recently $(p=0.31)$, or participated once versus multiple times $(p=0.27)$ in the HandbikeBattle.

\section{Experienced barriers and facilitators}

Of 96 respondents to questions about experienced barriers, $60 \%$ denied personal barriers (SCI/SB group: 61\%) and $64 \%$ denied environmental barriers (SCI/SB group: 59\%) (Fig. 2). Most participants mentioned about 5-6 personal facilitators and few environmental facilitators. Table 2 shows how often all potential barriers were mentioned. The personal barriers that were mentioned most frequently were time $(31 \%)$, less able to practice sport due to the disability $(17 \%)$ and pain complaints (15\%). The most often mentioned environmental barriers were transport to sport accommodation takes a lot of time (19\%) and not enough fellow athletes $(16 \%)$. The group with a SCI/SB showed similar results (Table 2), with one exception: only 3\% (vs. $15 \%$ in the total group) indicated that sports materials are expensive.

Table 3 shows how often all potential facilitators were mentioned. The most frequent personal facilitators were: health/condition improvement $(91 \%)$, getting physically stronger $(81 \%)$, and fun and/or relaxation (80\%). Family, partner and children were mentioned most frequently as environmental facilitator (13\%). These percentage were almost the same for the group with SCI/SB.

Those who participated less in sports indicated more personal $(p=0.004)$ and environmental barriers $(p=0.02)$ compared with those participating more in sports, with the largest differences in the barriers 'less able to practice sport due to the disability', 'not enough fellow athletes', and 'no suitable sport facilities in my area'. No differences were found between these groups regarding the sum score of experienced facilitators (Table 3 ). 
Table 1 Differences between responders and nonresponders to the survey among participants of the HandbikeBattle.

\begin{tabular}{|c|c|c|c|c|c|}
\hline & \multicolumn{2}{|c|}{ Responders $(N=96)$} & \multicolumn{2}{|c|}{ Nonresponders $(N=107)$} & \multirow[b]{2}{*}{$p$ value } \\
\hline & $N$ & Mean \pm SD or $\%$ & $N$ & Mean \pm SD or $\%$ & \\
\hline \multicolumn{6}{|l|}{ Gender } \\
\hline$\%$ Men & 96 & $76 \%$ & 107 & $78 \%$ & 0.80 \\
\hline \multicolumn{6}{|l|}{ Age } \\
\hline Years & 96 & $47.8 \pm 12.4$ & 103 & $39.7 \pm 13.5$ & $<0.001$ \\
\hline \multicolumn{6}{|l|}{ Disability } \\
\hline$\%$ Spinal cord injury & 57 & $62 \%$ & 66 & $69 \%$ & 0.15 \\
\hline$\%$ Amputation & 14 & $15 \%$ & 9 & $9 \%$ & \\
\hline$\%$ Spina bifida & 2 & $2 \%$ & 8 & $8 \%$ & \\
\hline$\%$ Other & 19 & $21 \%$ & 13 & $14 \%$ & \\
\hline \multicolumn{6}{|l|}{ Time since injury } \\
\hline Years & 84 & $13.2 \pm 12.0$ & 83 & $13.0 \pm 10.4$ & 0.91 \\
\hline $0-5$ years & 28 & $33 \%$ & 23 & $28 \%$ & \\
\hline $6-10$ years & 16 & $19 \%$ & 19 & $23 \%$ & \\
\hline $10-15$ years & 14 & $17 \%$ & 12 & $14 \%$ & \\
\hline$>15$ years & 26 & $31 \%$ & 29 & $35 \%$ & \\
\hline \multicolumn{6}{|l|}{ Sport participation $\mathrm{T} 1$} \\
\hline h/week median [IQR] & 66 & $5.3\left[\begin{array}{ll}3.0 & 7.5\end{array}\right]$ & 65 & $4.5\left[\begin{array}{ll}2.5 & 7.8\end{array}\right]$ & 0.61 \\
\hline \multicolumn{6}{|c|}{ Year of first HBB participation } \\
\hline 2013 & 20 & $21 \%$ & 22 & $21 \%$ & 0.31 \\
\hline 2014 & 14 & $15 \%$ & 25 & $23 \%$ & \\
\hline 2015 & 24 & $25 \%$ & 16 & $15 \%$ & \\
\hline 2016 & 15 & $15 \%$ & 19 & $18 \%$ & \\
\hline 2017 & 23 & $24 \%$ & 25 & $23 \%$ & \\
\hline \multicolumn{6}{|c|}{ Year of last HBB participation } \\
\hline 2013 & 7 & $7 \%$ & 8 & $7 \%$ & 0.24 \\
\hline 2014 & 9 & $9 \%$ & 22 & $21 \%$ & \\
\hline 2015 & 12 & $13 \%$ & 14 & $13 \%$ & \\
\hline 2016 & 18 & $19 \%$ & 17 & $16 \%$ & \\
\hline 2017 & 21 & $22 \%$ & 25 & $23 \%$ & \\
\hline 2018 & 29 & $30 \%$ & 21 & $20 \%$ & \\
\hline \multicolumn{6}{|c|}{ Number of participations in the HandbikeBattle } \\
\hline 1 & 44 & $46 \%$ & 57 & $53 \%$ & 0.26 \\
\hline 2 & 31 & $32 \%$ & 35 & $33 \%$ & \\
\hline 3 & 8 & $8 \%$ & 8 & $7 \%$ & \\
\hline 4 & 10 & $11 \%$ & 3 & $3 \%$ & \\
\hline 5 & 3 & $3 \%$ & 4 & $4 \%$ & \\
\hline
\end{tabular}

NB: T1: start of the 5 months training period.

$I Q R$ Interquartile range, $H B B$ HandbikeBattle.
The group that participated only once in the HandbikeBattle experienced more personal barriers than the group that participated multiple times $(p=0.005)$. No difference between these groups was found in environmental barriers or personal and environmental facilitators. Lastly, no differences were found in experienced barriers and facilitators between groups that participated in their (last) HandbikeBattle more or less recently.

\section{Discussion}

The majority of the responders to this study reported benefits of participation in the HandbikeBattle project. Most were still active in sports 1.5-5.5 years after their first participation in the event, although their sports participation after the event was similar to before. The most important personal barrier and facilitator for sport participation were 


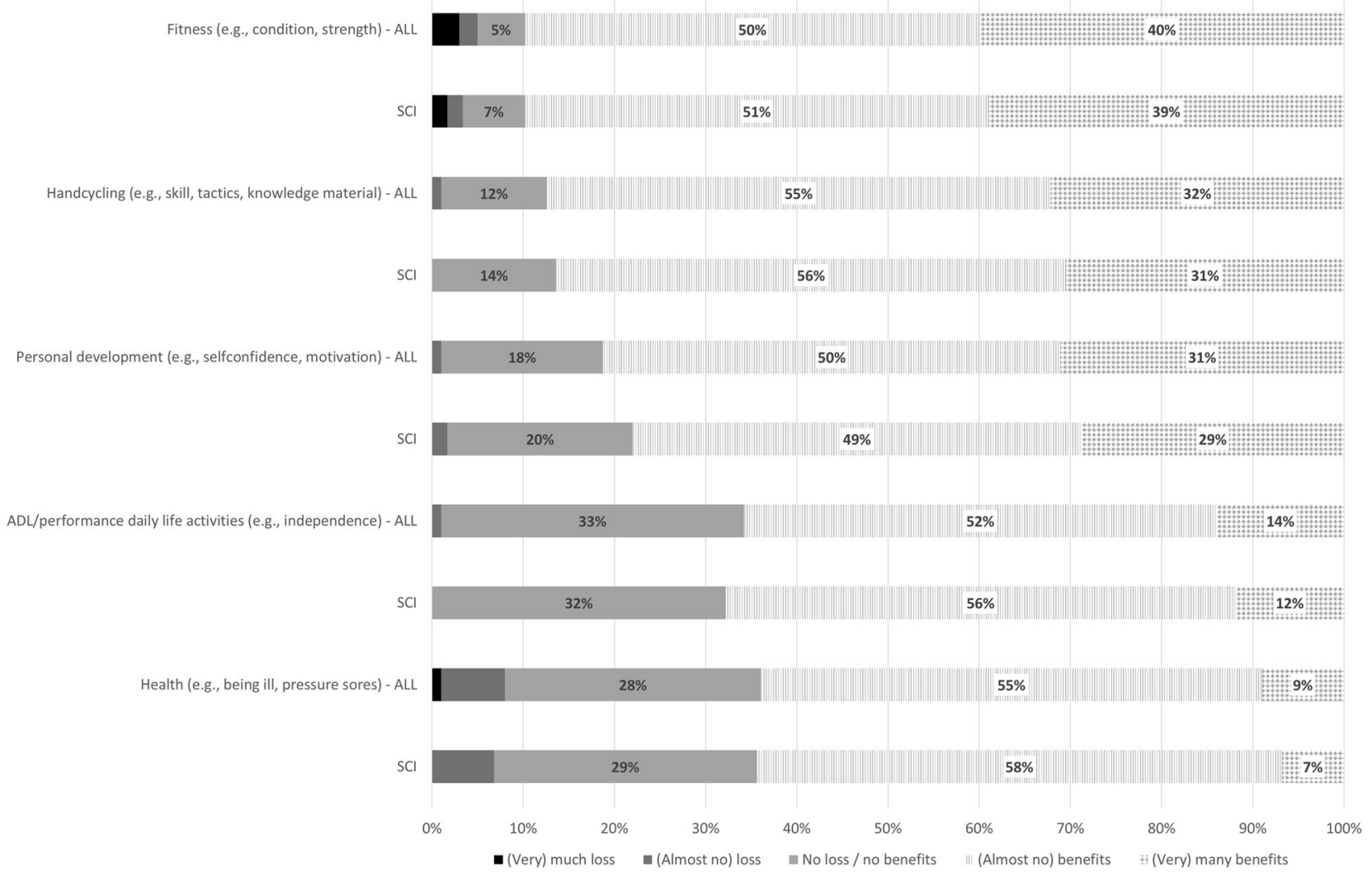

Fig. 1 Results on the questions about the experienced benefits on the domains fitness, handcycling, personal development, ADL/performance of daily life activities, and health. Percentage of answers are given in the categories '(very) much loss' to '(very) many benefits' for the total group (ALL; $N=96)$ and the group with SCI (SCI; $N=59$ ).

time and health/condition improvement, respectively. Time for transport to sport accommodation was mentioned most frequently as an environmental barrier while family, partner and children was the most frequently mentioned facilitator. Similar results were found when looking at the group with SCI/SB only. Furthermore, those who participated less in sports indicated more personal and environmental barriers, and those who participated only once in the HandbikeBattle experienced more personal barriers.

\section{Experienced benefits}

Most responders reported benefits, especially in the fitness domain, but also in the domains of health, personal development, and ADL performance. These results are in agreement with improvements in peak power output and peak oxygen uptake [9], peak expiratory flow [9], body composition [8,9], and mental status [10] during training for the HandbikeBattle event. An explanation for these experienced benefits might be that the HandbikeBattle project (free-living training plus event) meets the experiential aspects of participation (autonomy, belongingness, challenge, engagement, mastery, and meaning) [12] better than the regular exercise training programs. Group-based programming and leadership are identified as intervention conditions with potential to foster the experiential aspects of belongingness, mastery, and autonomy [12]. Our participants are part of a team with peers, i.e., have meetings and some group training sessions together, in the 5 months prior to the HandbikeBattle event and stay in a hotel in Austria for a week with over 100 other persons with a disability. Therefore, the participants are part of a community who share similar experiences and impairments (belongingness). We know from anecdotes, which was also previously reported [3], that many participants learn from each other (experiencing mastery) and this might have an effect on the reported benefits in the domains of personal development and ADL performance. As part of team development, the teams are allowed to include a handcyclist who participated in the HandbikeBattle before. This person often has a role as peer mentor, who can share disease-specific information, strategies for implementing lifestyle changes such as training, and provide psychosocial support to overcome challenges associated with living with a particular condition [13, 14].

Participants are also guided by instructors from the rehabilitation center with a strong exercise, sport, and disability-specific knowledge. These leaders can help 

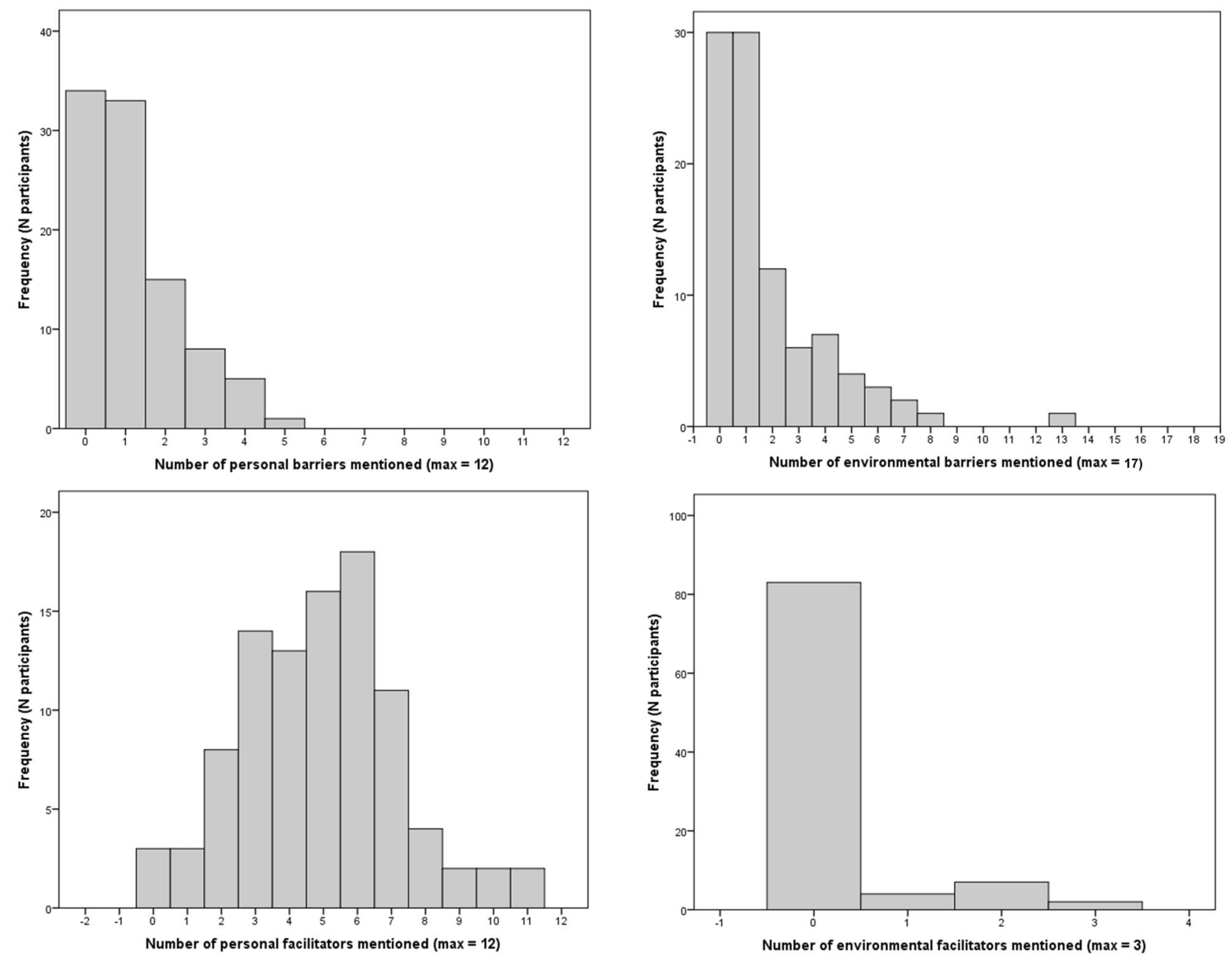

Fig. 2 Results of experienced barriers and facilitators of sports participation. Distribution of number of participants who mentioned none or $\geq 1$ barrier(s)/facilitator(s).

participants to achieve their goals and gain exercise and sport competence, which might lead to a sense of control and independence that allowed them to believe that they could continue the activity on their own (mastery and autonomy) [12]. During the training period the participants are appropriately challenged by increasing the training load, participating in longer/hillier handcycling tours, and ultimately by the HandbikeBattle event itself (challenge). Furthermore, having a goal to train for, i.e., a mountain race, gives the training purpose (meaning), and might lead to more involvement and motivation in the activity (engagement). Lastly, by finishing the mountain race they can show themselves and others (family, society) that they are capable of doing more than they previously thought (meaning). Unfortunately, we did not measure the effect of participating in the HandbikeBattle on these six experiential aspects of participation. Future studies could use the recently developed Measure of Experiential Aspects of Participation for People With Physical Disabilities [15].
A few responders experienced loss in one of the domains mentioned above. These responders mostly participated only once in the HandbikeBattle. Unfortunately, we did not include open questions in the survey asking for more information on this loss so we cannot elaborate on this.

\section{Sport participation}

The median sport hours per week was five, which is quite high when compared with the general Dutch adult population (2-4h/week) [16]. This high level might explain the lack of difference between sport participation prior to the training and at follow-up. Maybe participants already started to train before the medical screening because they knew they were probably going to participate in the event.

\section{Experienced barriers and facilitators}

Although levels of current sports participation were high, part of the responders nevertheless experienced barriers to 
Table 2 Experienced barriers of sports participation after participating in the HandbikeBattle of the total group $(N=96)$, for the groups that participate in sport more or less than $5 \mathrm{~h} /$ week, and for SCI only.

\begin{tabular}{|c|c|c|c|c|}
\hline & $\begin{array}{l}\text { All responders } \\
(N=96)\end{array}$ & $\begin{array}{l}\leq 5 \text { sport hours/week } \\
(N=49)\end{array}$ & $\begin{array}{l}>5 \text { sport hours/week } \\
(N=47)\end{array}$ & $\begin{array}{l}\text { SCI only } \\
(N=59)\end{array}$ \\
\hline \multicolumn{5}{|l|}{ Personal factors } \\
\hline It costs a lot of time/I do not have (enough time) & $31 \%$ & $37 \%$ & $26 \%$ & $37 \%$ \\
\hline Due to disorder less able to practice sports or move & $17 \%$ & $25 \%$ & $9 \%$ & $14 \%$ \\
\hline Pain complaints & $15 \%$ & $16 \%$ & $13 \%$ & $10 \%$ \\
\hline Not a lot of energy/quickly tired & $14 \%$ & $12 \%$ & $15 \%$ & $12 \%$ \\
\hline Dependent on other people to be able to move & $8 \%$ & $12 \%$ & $4 \%$ & $10 \%$ \\
\hline I have an injury & $7 \%$ & $10 \%$ & $4 \%$ & $9 \%$ \\
\hline Fear of injury & $4 \%$ & $2 \%$ & $6 \%$ & $7 \%$ \\
\hline I am embarrassed of my disorder & $1 \%$ & $2 \%$ & $0 \%$ & $0 \%$ \\
\hline Not comfortable between other participants & $1 \%$ & $2 \%$ & $0 \%$ & $0 \%$ \\
\hline $\begin{array}{l}\text { I do not like to move or mostly do not feel } \\
\text { like moving }\end{array}$ & $1 \%$ & $2 \%$ & $0 \%$ & $0 \%$ \\
\hline I feel watched during sports practice & $0 \%$ & $0 \%$ & $0 \%$ & $0 \%$ \\
\hline \multicolumn{5}{|l|}{ Environmental factors } \\
\hline $\begin{array}{l}\text { Transport to sports accommodation takes a lot } \\
\text { of time }\end{array}$ & $19 \%$ & $18 \%$ & $19 \%$ & $12 \%$ \\
\hline Not enough fellow athletes & $16 \%$ & $27 \%$ & $4 \%$ & $19 \%$ \\
\hline There are no suitable sport facilities in my area & $15 \%$ & $22 \%$ & $6 \%$ & $14 \%$ \\
\hline Accommodation is not (sufficiently) adjusted & $15 \%$ & $12 \%$ & $17 \%$ & $12 \%$ \\
\hline Sports materials are expensive & $15 \%$ & $8 \%$ & $21 \%$ & $3 \%$ \\
\hline $\begin{array}{l}\text { No/not enough professional guidance during } \\
\text { sports practice }\end{array}$ & $13 \%$ & $14 \%$ & $11 \%$ & $10 \%$ \\
\hline Transport to sports accommodation is expensive & $12 \%$ & $10 \%$ & $13 \%$ & $10 \%$ \\
\hline Participation in training/classes is/are expensive & $8 \%$ & $10 \%$ & $6 \%$ & $5 \%$ \\
\hline Sports materials are not (sufficiently) adjusted & $7 \%$ & $8 \%$ & $6 \%$ & $9 \%$ \\
\hline Sports accommodation is expensive & $6 \%$ & $2 \%$ & $11 \%$ & $7 \%$ \\
\hline Training/classes is/are not (sufficiently) adjusted & $5 \%$ & $6 \%$ & $4 \%$ & $2 \%$ \\
\hline $\begin{array}{l}\text { Not enough help from the environment for } \\
\text { participation in sports }\end{array}$ & $5 \%$ & $6 \%$ & $4 \%$ & $5 \%$ \\
\hline I miss information about sport facilities & $4 \%$ & $8 \%$ & $0 \%$ & $5 \%$ \\
\hline Sports materials are not (sufficiently) available & $4 \%$ & $4 \%$ & $4 \%$ & $2 \%$ \\
\hline Cannot practice sports with peers & $4 \%$ & $4 \%$ & $4 \%$ & $3 \%$ \\
\hline People with a disability are not (fully) accepted & $4 \%$ & $4 \%$ & $4 \%$ & $2 \%$ \\
\hline Have not yet found a suitable sport & $3 \%$ & $6 \%$ & $0 \%$ & $3 \%$ \\
\hline
\end{tabular}

participate in sport. The most frequent personal barriers were time $(31 \%)$, disability (17\%), and pain (15\%). In a previous study among Dutch people with a disability, the disability and fatigue/lack of energy were the most frequently mentioned personal barriers [17]. Pain was also often mentioned as a barrier for physical activity in another study [18], as well as laziness [18] or lack of motivation [19].

The most frequent environmental barriers were transport to sport accommodation (19\%) and not enough peer athletes $(16 \%)$. Problems with transport is also often mentioned in other studies with respect to physical activity and sport participation, either regarding costs or time involved $[3,19]$.

In line with the high sports participation, most responders mentioned much more facilitators than barriers. The most frequent personal facilitators were health and condition improvement, and fun and/or relaxation, which was in agreement with previous studies [3, 17, 20].

Family, partner, and children were mentioned by only $13 \%$ of the respondents but was the most mentioned environmental facilitator. This factor was also mentioned in other studies [17, 19]. In studies on barriers and facilitators of everyday physical activity [19] and sports [17], it was 
Table 3 Experienced facilitators of sports participation after participating in the HandbikeBattle of the total group $(N=96)$, for the groups that participate in sport more or less than $5 \mathrm{~h} /$ week, and for SCI only.

\begin{tabular}{|c|c|c|c|c|}
\hline & $\begin{array}{l}\text { All responders } \\
(N=96)\end{array}$ & $\begin{array}{l}\leq 5 \text { sport hours/ } \\
\text { week }(N=49)\end{array}$ & $\begin{array}{l}>5 \text { sport hours/ } \\
\text { week }(N=47)\end{array}$ & $\begin{array}{l}\text { SCI only } \\
(N=59)\end{array}$ \\
\hline \multicolumn{5}{|l|}{ Personal factors } \\
\hline Health/condition improvement & $91 \%$ & $88 \%$ & $94 \%$ & $92 \%$ \\
\hline Getting physically stronger & $81 \%$ & $80 \%$ & $83 \%$ & $80 \%$ \\
\hline Fun/relaxation & $80 \%$ & $78 \%$ & $83 \%$ & $86 \%$ \\
\hline Sociability/social contacts & $56 \%$ & $55 \%$ & $57 \%$ & $49 \%$ \\
\hline Weight loss & $44 \%$ & $45 \%$ & $43 \%$ & $44 \%$ \\
\hline Lose energy & $38 \%$ & $33 \%$ & $43 \%$ & $39 \%$ \\
\hline Competition aspect/winning & $26 \%$ & $20 \%$ & $32 \%$ & $27 \%$ \\
\hline Increase self-esteem & $23 \%$ & $22 \%$ & $23 \%$ & $22 \%$ \\
\hline Being less dependent on others & $15 \%$ & $10 \%$ & $19 \%$ & $14 \%$ \\
\hline Learn something new & $14 \%$ & $10 \%$ & $17 \%$ & $15 \%$ \\
\hline Acceptation of disability & $12 \%$ & $6 \%$ & $17 \%$ & $12 \%$ \\
\hline Learning to deal with disability & $12 \%$ & $6 \%$ & $17 \%$ & $12 \%$ \\
\hline \multicolumn{5}{|l|}{ Environmental factors } \\
\hline Support of family, partner, children & $13 \%$ & $6 \%$ & $19 \%$ & $9 \%$ \\
\hline $\begin{array}{l}\text { Support of friends, acquaintances, } \\
\text { colleagues, fellow athletes }\end{array}$ & $9 \%$ & $4 \%$ & $15 \%$ & $7 \%$ \\
\hline $\begin{array}{l}\text { On the advice of general } \\
\text { practitioner, physical therapist or } \\
\text { medical specialist }\end{array}$ & $3 \%$ & $2 \%$ & $4 \%$ & $0 \%$ \\
\hline
\end{tabular}

found that advice from rehabilitation professionals was the most frequently mentioned facilitator. This is in contrast with the present study, in which only $3 \%$ of the participants indicated advice from rehabilitation professionals as a facilitator. However, it is important to emphasize that our responders were stimulated and supported to start training before the HandbikeBattle. It seems that when people with a disability are intrinsically motivated and know how to participate in sports at home, they do not need the constant support of the rehabilitation center to maintain exercising.

\section{Limitations of the study}

There are several limitations of this study. Firstly, the results of this study cannot be generalized to the whole population with a disability. Not every person wants to be involved in such a challenging event. Furthermore, only $47 \%$ of the participants of the HandbikeBattle study filled out the survey of the present study. However, the responders and nonresponders were not significantly different at the time of the medical screening regarding personal characteristics, except for age, and sport participation.

Secondly, the time between last participation in the HandbikeBattle and the time of data collection of the present survey varied between 0.5 and 5.5 years. Although no differences were found according to time since first participation in the event, there might have been a recall bias that could have an effect on the results.
Lastly, there were some missing values regarding sport participation at the time of the medical screening, so the analysis of change in sports participation was based on a smaller number of participants. Moreover, it might be possible that the participants of the HandbikeBattle had already started to be more active before the first test occasion. Finally, the sport hours per week were self-reported and, therefore, could have been overestimated [21].

\section{Conclusion}

Based on the results of this study, it seems that training for and participating in the HandbikeBattle leads to high sport participation and experienced benefits in several domains, even on the long term. Therefore, the findings highlight the role sports challenges can have in establishing a sustainable active lifestyle among people with disabilities. The experienced health and fitness benefits, and the fun and social aspects of sport participation for people seem the major motivators for sport participation.

Acknowledgements The assistance of Wies Achtereekte during the data collection is greatly appreciated.

HandbikeBattle group Bram van Gemeren ${ }^{9}$, Mark van de Mijll Dek$\operatorname{ker}^{10}$, Karin Postma ${ }^{11}$, Linda van Vliet ${ }^{12}$, Misha Metsaars ${ }^{13}$, Eric Helmantel $^{14}$, Lise Wilders ${ }^{15}$, Maremka Zwinkels ${ }^{16}$, Paul Grandjean ${ }^{17}$, Selma Overbeek $^{18}$, Wilbert Snoek ${ }^{19}$, Alinda Gjaltema ${ }^{20}$ 
${ }^{9}$ Rehabilitation Center Het Roessingh, Enschede, The Netherlands; ${ }^{10}$ Rehabilitation Center Heliomare, Wijk aan Zee, The Netherlands; ${ }^{11}$ Rehabilitation Center Rijndam, Rotterdam, The Netherlands; ${ }^{12}$ Reade Center for Rehabilitation \& Rheumatology, Amsterdam, The Netherlands; ${ }^{13}$ Libra Rehabilitation \& Audiology, Location Blixembosch, Eindhoven, The Netherlands; ${ }^{14}$ University Medical Center Groningen, Location Beatrixoord, Haren, The Netherlands; ${ }^{15}$ Sint Maartenskliniek, Nijmegen, The Netherlands; ${ }^{16}$ Rehabilitation Center De Hoogstraat, Utrecht, The Netherlands; ${ }^{17}$ Rehabilitation Center Adelante, Hoensbroek, The Netherlands; ${ }^{18}$ Rehabilitation Center Tolbrug, Den Bosch, The Netherlands; ${ }^{19}$ Rehabilitation Center Revant, Breda, The Netherlands; ${ }^{20}$ Rehabilitation Center Vogellanden, Zwolle, The Netherlands

\section{Compliance with ethical standards}

Conflict of interest The authors declare that they have no conflict of interest.

Publisher's note Springer Nature remains neutral with regard to jurisdictional claims in published maps and institutional affiliations.

\section{References}

1. van den Berg-Emons RJ, Bussmann JB, Stam HJ. Accelerometrybased activity spectrum in persons with chronic physical conditions. Arch Phys Med Rehabil. 2010;91:1856-61.

2. Jaarsma EA, Dijkstra PU, Geertzen JH, Dekker R. Barriers to and facilitators of sports participation for people with physical disabilities: a systematic review. Scand J Med Sci Sports. 2014;24:871-81.

3. Stephens C, Neil R, Smith P. The perceived benefits and barriers of sport in spinal cord injured individuals: a qualitative study. Disabil Rehabil. 2012;34:2061-70.

4. de Groot S, Post MW, Snoek GJ, Schuitemaker M, van der Woude LH. Longitudinal association between lifestyle and coronary heart disease risk factors among individuals with spinal cord injury. Spinal Cord. 2013;51:314-8.

5. van Koppenhagen CF, Post M, de Groot S, van Leeuwen C, van Asbeck F, Stolwijk-Swuste J, et al. Longitudinal relationship between wheelchair exercise capacity and life satisfaction in patients with spinal cord injury: a cohort study in the Netherlands. J Spinal Cord Med. 2014;37:328-37.

6. Martin Ginis KA, van der Scheer JW, Latimer-Cheung AE, Barrow A, Bourne C, Carruthers P, et al. Evidence-based scientific exercise guidelines for adults with spinal cord injury: an update and a new guideline. Spinal Cord. 2018;56:308-21.

7. de Groot S, Postma K, van Vliet L, Timmermans R, Valent LJ. Mountain time trial in handcycling: exercise intensity and predictors of race time in people with spinal cord injury. Spinal Cord. 2014;52:455-61.
8. de Groot S, Kouwijzer I, Baauw M, Broeksteeg R, Valent LJ. Effect of self-guided training for the HandbikeBattle on body composition in people with spinal cord injury. Spinal Cord Ser Cases. 2018;4:79.

9. Hoekstra S, Valent L, Gobets D, van der Woude L, de Groot S. Effects of four-month handbike training under free-living conditions on physical fitness and health in wheelchair users. Disabil Rehabil. 2017;39:1581-8.

10. Kouwijzer I, de Groot S, van Leeuwen CM, Valent LJ, van Koppenhagen CF, van der Woude LH, et al. Changes in quality of life during training for the HandbikeBattle and associations with cardiorespiratory fitness. Arch Phys Med Rehabil. 2020;101:1017-24.

11. Jaarsma EA, Geertzen JH, de Jong R, Dijkstra PU, Dekker R. Barriers and facilitators of sports in Dutch Paralympic athletes: an explorative study. Scand J Med Sci Sports. 2014;24:830-6.

12. Shirazipour CH, Evans MB, Leo J, Lithopoulos A, Martin Ginis KA, Latimer-Cheung AE. Program conditions that foster quality physical activity participation experiences for people with a physical disability: a systematic review. Disabil Rehabil. 2020;42:147-55.

13. Colon-Semenza C, Latham NK, Quintiliani LM, Ellis TD. Peer coaching through mHealth targeting physical activity in people with Parkinson disease: feasibility study. JMIR Mhealth Uhealth. 2018;6:e42.

14. Ginis KA, Nigg CR, Smith AL. Peer-delivered physical activity interventions: an overlooked opportunity for physical activity promotion. Transl Behav Med. 2013;3:434-43.

15. Caron JG, Martin Ginis KA, Rocchi M, Sweet SN. Development of the measure of experiential aspects of participation for people with physical disabilities. Arch Phys Med Rehabil. 2019;100:67-77.

16. Duijf M, van den Berg S, van Houten J, Wendel-Vos W, Hiemstra A, Duijvestijn M. Een leven lang bewegen en sporten. 2017. https://www.allesoversport.nl/artikel/een-leven-lang-bewegen-ensporten/.

17. Jaarsma EA, Dekker R, Geertzen JH, Dijkstra PU. Sports participation after rehabilitation: barriers and facilitators. J Rehabil Med. 2016;48:72-9.

18. Mat Rosly M, Halaki M, Mat Rosly H, Davis GM, Hasnan N, Husain R. Malaysian adaptation of the physical activity scale for individuals with physical disabilities in individuals with spinal cord injury. Disabil Rehabil. 2019:1-9.

19. Vissers M, van den Berg-Emons R, Sluis T, Bergen M, Stam H, Bussmann H. Barriers to and facilitators of everyday physical activity in persons with a spinal cord injury after discharge from the rehabilitation centre. J Rehabil Med. 2008;40:461-7.

20. Wu SK, Williams T. Factors influencing sport participation among athletes with spinal cord injury. Med Sci Sports Exerc. 2001;33:177-82.

21. van den Berg-Emons RJ, L'Ortye AA, Buffart LM, Nieuwenhuijsen C, Nooijen CF, Bergen MP, et al. Validation of the physical activity scale for individuals with physical disabilities. Arch Phys Med Rehabil. 2011;92:923-8. 